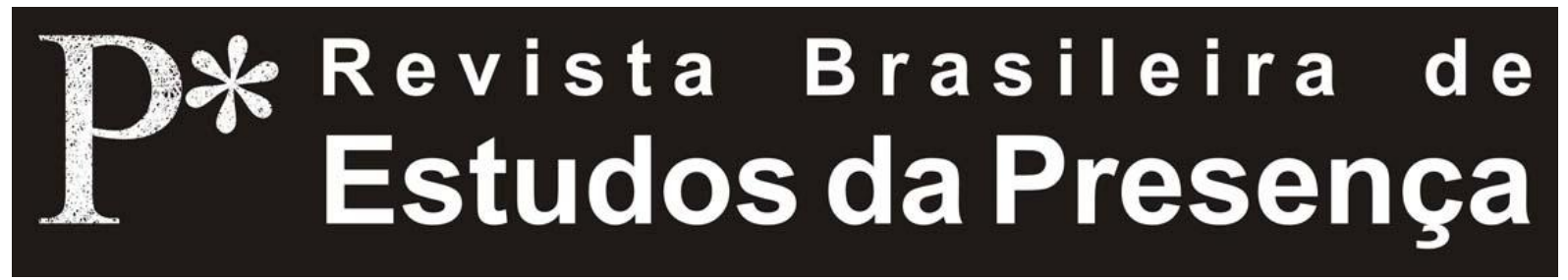

DOI - http://dx.doi.org/10.1590/2237-266023722

ISSN 2237-2660

\title{
La corporeidad y el poder realizador del actor
}

\author{
Gabriela Pérez Cubas
}

Universidad Nacional del Centro de la Provincia de Buenos Aires - Argentina

RESUMEN - La corporeidad y el poder realizador del actor El presente artículo trata de una serie de conceptos vinculados a la noción de cuerpo y subjetividad en el entrenamiento cinestésico y expresivo del actor. A tal fin, se propone un diálogo entre los estudios sobre las configuraciones de cuerpo en las sociedades occidentales que desarrollan, desde la óptica de la antropología, el sociólogo y antropólogo francés David Le Breton y desde el campo de los estudios sobre danza, estudios performáticos y políticas del movimiento el ensayista André Lepecki.

Palabras claves: Cuerpo. Actor. Subjetividad. Entrenamiento. Performance.

ABSTRACT - The corporality and the performative power of the actor - This article discusses different concepts linked to the notion of body in contemporary western societies from the point of view of French Sociologist-Anthropologist David Le Breton. His concept of body will be related in this essay with perceptions of body and subjectivity by Dance and Performance Studies theorist André Lepecki in his discussion of movement and politics. The present study aims at deepening the reflection of performers and theorists on the actor's expressive movement training.

Key words: Body. Actor. Subjectivity. Training. Performance.

RÉSUMÉ - La corporéité et le pouvoir réalisateur de l'acteur Le présent article aborde une série de concepts liés à la notion de corps et de subjectivité dans l'entraînement cinesthésique et

Gabriela Pérez Cubas, La corporeidad y el poder realizador del actor

R.bras.est.pres., Porto Alegre, v.1, n.2, p. 370-384, jul./dez., 2011.

Disponível em http://www.seer.ufrgs.br/presenca 
expressif de l'acteur. Pour ce faire, il propose un dialogue interdisciplinaire entre les diverses recherches portant sur les configurations du corps dans les sociétés occidentales, s'appuyant notamment sur les travaux de l'anthropologue et sociologue français David Le Breton et sur les études menées par l'essayiste André Lepecki à propos de la dance, de la performance et des politiques du mouvement.

Mots clés: Corps. Acteur. Subjectivité. Entraînement. Performance.

\section{¿Qué cuerpo? ¿Qué técnicas?}

Una de las primeras cuestiones a las que se enfrenta quien pretenda establecer una metodología de entrenamiento corporal para el actor es definir cuál es el perfil de actor al que se destina ese entrenamiento. Si concordamos que en la actualidad existe una multiplicidad de poéticas teatrales y de técnicas de trabajo corporal que pueden resultar pertinentes para el desarrollo de las mismas, se plantea entonces la necesidad de establecer criterios de selección para elaborar una propuesta coherente y sistematizada. Tal vez, el paso inicial para definir criterios sea preguntarnos ¿qué es lo que necesita entrenar una actor?, ¿para qué?

Probablemente la primera confusión surja del hecho de denominar entrenamiento a un trabajo que implica sensibilizar la motricidad y la expresividad en individuos que, fundamentalmente, cuentan con sus emociones, sus sensaciones y sus percepciones para realizar su tarea. La palabra entrenamiento remite, generalmente, a concepciones mecanicistas que entienden al cuerpo como un objeto que el sujeto posee y al que se debe instruir, convirtiéndolo en receptáculo de todas aquellas disciplinas que puedan obtener de él el más grande de los rendimientos.

Sin embargo, no se trata de descartar el concepto de entrenamiento, porque supone una forma organizada de ejercitación en base a la aplicación de técnicas específicas para la escena. Considero que el problema reside en establecer cuál es la concepción de cuerpo que subyace a una propuesta de entrenamiento. Es decir, ¿El cuerpo del actor es un objeto a moldear? ¿Al iniciar un 
proceso de entrenamiento, el actor parte de la nada? ¿O es la corporeidad como "carnalidad historiada" (Matoso, 2001, p. 11) la que debe considerarse como punto de partida para un entrenamiento teatral?

A primera vista, esta discusión parece ya superada, pues hay evidencias irrefutables que demuestran que el ser humano es un sistema de sistemas vitales y sensibles. Sin embargo, si interrogamos algunas de las propuestas de entrenamiento actoral que circulan en la actualidad a la luz de las cuestiones antes planteadas, es posible detectar la vigencia de un imaginario del cuerpo que plantea lo contrario. Porque a pesar de que los discursos sobre el cuerpo han cambiado - y tal vez muchas propuestas de entrenamiento adhieran a estos discursos - los modos en que se aplican, se transmiten $y$ se in-corporan las técnicas de entrenamiento responden a un paradigma dualista. En él lo que subyace es la noción de cuerpo como objeto, como posesión del sujeto, de subjetividad escindida del cuerpo.

Esta es una problemática que excede el análisis de casos particulares. La cultura occidental ha construido a lo largo de siglos un imaginario del cuerpo como maquina maravillosa que el sujeto posee. Nuestra concepción de cuerpo se encuentra profundamente imbricada con los saberes mecanicistas que sobre él se han transmitido.

\section{La cultura encarnada}

Según el antropólogo y sociólogo francés David Le Breton (Le Breton, 1995) el conocimiento del cuerpo es, en primer término, cultural. Las diversas representaciones sociales le otorgan al cuerpo una determinada posición dentro del simbolismo general de la sociedad construyendo una definición de persona. Una cultura es un conjunto de símbolos. El cuerpo es una construcción simbólica, no es una realidad en sí mismo, el cuerpo parece evidente, pero nada es más intangible. Los símbolos de la cultura en la que vivimos se encarnan en nuestros cuerpos.

El ser humano en la medida que se relaciona incorpora, hace cuerpo el imaginario social de su entorno:

Gabriela Pérez Cubas, La corporeidad y el poder realizador del actor

R.bras.est.pres., Porto Alegre, v.1, n.2, p. 370-384, jul./dez., 2011.

Disponível em http://www.seer.ufrgs.br/presenca 
Las representaciones sociales le asignan al cuerpo una posición determinada dentro del simbolismo general de la sociedad. Sirven para nombrar las diferentes partes que lo componen y las funciones que cumplen, hacen explícitas sus relaciones, penetran el interior invisible del cuerpo para depositar allí imágenes precisas, le otorgan una ubicación en el cosmos, en la ecología de la comunidad humana. Este saber aplicado al cuerpo es, en primer término, cultural (Le Breton, 1995, p.13).

En estrecha relación con el imaginario social, el sujeto construye la imagen de su cuerpo. Para Le Breton, la imagen del cuerpo es "la representación que el sujeto hace del cuerpo; la manera en que se le aparece más o menos conscientemente a través del contexto social y cultural de su historia personal" (Le Breton, 1995, p.146).

El autor identifica cuatro ejes, cuyo entrecruzamiento estructura existencialmente la imagen del cuerpo, dependiendo del contexto social, cultural, interpersonal y personal, en el cual se inserta el sujeto, estos son definidos como: a) forma: sentimiento de unidad de las diferentes partes del cuerpo, de aprehensión como un todo de sus límites precisos en el espacio; $b$ ) contenido: la imagen del cuerpo como un universo coherente y familiar en el cual se inscriben sensaciones previsibles y reconocibles; c) saber: el conocimiento que el sujeto posee acerca de la idea que la sociedad en la que habita tiene de la espesura del cuerpo, de cuál es su constitución, de cómo se organizan los órganos y las funciones; d) valor: es la interiorización que el sujeto hace del juicio social respecto de los atributos físicos que lo caracterizan (lindo/feo, joven/ viejo, alto/bajo, flaco/gordo, etc.). De acuerdo con la clase social y la historia personal en la que estructura su relación con el mundo, el sujeto se apropia de un juicio que marca con su sello la imagen que él construye de su cuerpo y su autoestima.

Entre los tres primeros ejes no existen mayores conflictos. Ellos son puntos de referencia que cambian a medida que el hombre vive y le otorgan una sensación de armonía. Con esta imagen del cuerpo, pueden medirse las

Gabriela Pérez Cubas, La corporeidad y el poder realizador del actor

R.bras.est.pres., Porto Alegre, v.1, n.2, p. 370-384, jul./dez., 2011.

Disponível em http://www.seer.ufrgs.br/presenca 
acciones del pasado y las que se harán en una relación familiar con el mundo. El cuarto eje es el que mayores conflictos acarrea, porque representa el punto de vista del otro y obliga al sujeto a verse desde una óptica más o menos favorable en relación con los demás.

La relación con los otros, garantiza al sujeto la alianza social, de la cual el símbolo es la materia prima. El símbolo estructura tanto la identidad personal como social, otorgando valor al intercambio entre sujetos.

En las últimas décadas, a causa del fenómeno de globalización económico y cultural, los procesos sociales evolucionaron a una velocidad hasta entonces poco conocida. La vertiginosidad y la multiplicidad de referencias caracterizan hoy las relaciones sociales. Pero pocas veces, las construcciones simbólicas de la cultura a la que el sujeto pertenece, consiguen acompañar el ritmo de los nuevos intercambios. Este desfasaje genera en el sujeto un divorcio entre el accionar social y su capacidad de integrar simbólicamente tales actos a la experiencia subjetiva de su acción.

El cuerpo se encuentra en el centro de esta escisión entre acción social y experiencia subjetiva. Dado que la subjetividad, que podríamos también denominar interioridad, no encuentra anclaje en tierras demasiado firmes, el cuerpo como objeto concreto, como imagen comunicable a la sociedad, se convierte en el protagonista de las búsquedas de sentido. Frente a la desestructuración de las prácticas sociales, el sujeto emprende búsquedas personales que restablezcan la relación entre acción y sentido. Entonces, el cuerpo contemporáneo desempeña el rol de una pantalla:

El hombre común proyecta sobre su cuerpo un saber compuesto que se parece a un traje de Arlequín, un saber hecho de zonas sombrías, de imprecisiones, de confusiones, de conocimientos más o menos abstractos a los que les otorga un cierto relieve [...] En las sociedades occidentales asistimos a una multiplicación de las representaciones del cuerpo, más o menos organizadas y rivales entre sí. Cada uno "construye" una visión personal del cuerpo y la arma como si fuese un rompecabezas, sin preocuparse por las

Gabriela Pérez Cubas, La corporeidad y el poder realizador del actor

R.bras.est.pres., Porto Alegre, v.1, n.2, p. 370-384, jul./dez., 2011.

Disponível em http://www.seer.ufrgs.br/presenca 
contradicciones o por la heterogeneidad del saber que toma prestado (Le Breton, 1995, p.88).

La relación sujeto cuerpo, está ahora invertida: la interioridad se muestra en el cuerpo. Como afirma Le Bretón, no se trata de un cambio de paradigma. Esta revalorización del cuerpo es, en esencia la evolución de la filosofía mecanicista y la perpetuación de un imaginario dualista, que desde hace varios siglos sustenta la cultura occidental.

\section{Una máquina maravillosa}

Tal vez uno de los conceptos más importantes para entender la relación del hombre occidental con su cuerpo sea el de dualismo: pensamiento que divide la mente (esencia del sujeto según esta postura) del cuerpo. Los orígenes de esa concepción, según Le Breton, se establecen hacia la segunda mitad de la Edad Media. Entonces, producto de modificaciones sociales y económicas, emergen las sociedades capitalistas y el individualismo en su seno. Una nueva clase social se diferencia del conjunto: la burguesía, como sector económicamente diferente del resto del pueblo. Este hecho marca una fractura en la unidad del cuerpo social medieval, hasta entonces cuerpo comunitario. El nuevo burgués busca diferenciarse del conjunto social, rechazando los comportamientos del vulgo y cerrándose sobre sí mismo ${ }^{1}$. Se instaura el cuerpo como una barrera entre el sujeto y su entorno y surge la idea del individuo, independiente en su pensamiento y su accionar, tanto dentro del universo social cuanto cósmico. El hombre se descubre a si mismo poseedor de un cuerpo el cual, disociado de la persona, se convierte en una realidad autónoma, en un objeto capaz de ser estudiado científicamente, alejado de cualquier referencia al sujeto, a la naturaleza, a la sociedad como conjunto de sujetos ${ }^{2}$.

El mundo es comprendido a través del cálculo y el cuerpo - reducido a una realidad accidental, a una máquina que genera vida - es considerado como uno de esos objetos. Esta nueva concepción de cuerpo-objeto, 
que el sujeto posee, marca la primacía del pensamiento mecanicista.

Así, el racionalismo emergente en los siglos XVII y XVIII cambia totalmente los criterios de conocimiento. El saber basado en las tradiciones es lentamente substituido por un saber de especialistas, los únicos aptos para apreciar los criterios de lo verdadero, partiendo de un conjunto de reglas que pretenden una validez independiente de las culturas y de la historia. El desarrollo de una racionalidad del cuerpo forma parte de esta lógica y genera una analítica social de su funcionamiento que, como dice Le Bretón, lleva al paroxismo la dualidad entre mente y cuerpo. Este último se alinea con las otras máquinas de la producción, en lo que Michel Foucault (Foucault: 2001:141) denominó como "Una anatomía política, que es igualmente una mecánica del poder" y que supone la prolongación del pensamiento mecanicista en los movimientos corporales, racionalizando la fuerza de trabajo del sujeto y coordinando las instituciones sociales (fábricas, escuelas, hospitales, cárceles, iglesias, etc.) según un cálculo que debe lograr la docilidad de los individuos y la mayor eficacia en las acciones emprendidas.

Aunque en extremo resumido, este es el fundamento ideológico que Le Breton atribuye a la relación del hombre occidental con el cuerpo. Este antropólogo afirma que el hombre en la inevitable fascinación que por el cuerpo siente, llegó a elaborar, dentro de un racionalismo mecanicista, una concepción de cuerpo como máquina maravillosa. Este es un intento por reparar la dignidad perdida del cuerpo, otorgándole una validez que no tendría si fuese sólo un organismo. Es sobre este reduccionismo metafórico que, según el autor, se edificó el conocimiento y la relación con el cuerpo en occidente.

La estructura institucional de nuestras sociedades responde mayoritariamente al modelo europeo, instaurando la distinción entre sujeto y cuerpo. Un buen ejemplo es el desarrollo de la medicina occidental, que separa al sujeto de su cuerpo para estudiar en este último sus mecanismos de funcionamiento. Los saberes 
biomédicos del cuerpo, legitimados y transmitidos por las instituciones, son los que los individuos in-corporan para conocer su cuerpo y el de los otros.

El hermetismo con que los saberes biomédicos explican el cuerpo humano - expoliado de todo simbolismo, definido por un lenguaje ajeno a la realidad cotidiana, excluyendo completamente al individuo - es uno de los motivos del vaciamiento simbólico del cuerpo. Quizá por ello coexistan en la actualidad, dentro de un mismo contexto cultural, saberes tradicionales y alternativos, a los que los individuos recurren en procura de una comprensión más integradora de la existencia humana. El objetivo es restituir al hombre su dimensión simbólica, su valor como integrante de un universo holístico.

\section{El cuerpo, alter ego del sujeto}

En esta búsqueda de respuestas, el sujeto busca crear una simbología propia para subjetividad el cuerpo, como forma de recuperar la corporeidad perdida. Sin embargo, aunque esto representa una apertura a nuevos comportamientos y plantea nuevas formas de ver y pensar la corporeidad, no consigue reparar la pérdida.

En nuestra vida cotidiana el cuerpo permanece relegado detrás de la ritualización de las acciones, que hacen al comportamiento humano inteligible posibilitando su comunicación y desempeño social. Los intercambios cotidianos entre sujetos se encuentran condicionados por una red de expectativas corporales recíprocas. Todas las expresiones, gestos, posturas, etc., son compartidas por los sujetos dentro de un estrecho margen de variación. Existe un sensorio común que regula las experiencias somáticas y las hace inteligibles para el otro, convirtiendo el comportamiento del sujeto en un reflejo del comportamiento de los otros. Así, el cuerpo funciona como un alter ego del sujeto y mientras tanto no deja de producir y registrar sentidos, aunque la mente no tenga registro consciente de ellos. Como afirma Le Bretón, el lugar del cuerpo en los rituales de la vida cotidiana es el de claro-oscuro, el de la presenciaausencia.

Gabriela Pérez Cubas, La corporeidad y el poder realizador del actor

R.bras.est.pres., Porto Alegre, v.1, n.2, p. 370-384, jul./dez., 2011.

Disponível em http://www.seer.ufrgs.br/presenca 
Tal vez, sea esa ausencia la que ha pretendido llenar la multiplicidad de técnicas corporales que en las últimas décadas invadieron el mercado. En un abanico que se despliega desde las técnicas orientales, pasando por la astrología y llegando hasta el alpinismo, esa eclosión de técnicas promete un "retorno al cuerpo." Sin embargo, buena parte de las diversas técnicas que hoy circulan, se hallan determinadas por un modelo de cuerpo definido por la autoridad de los medios masivos de comunicación que sustentan y amplifican hasta el paroxismo el imaginario dualista: un cuerpo sano, esbelto, joven y fundamentalmente bello. Este modelo de cuerpo, basado en los cánones de la cultura euro norteamericana pareciera tener como objetivo primero negar una de las características fundamentales del cuerpo, su condición de finitud y su evolución desde el nacimiento hacia la muerte. Aunque a veces pueda estar enmascarado detrás de propuestas más o menos interesantes, este modelo de cuerpo, ideado por y para el consumo, permanece.

Muchas de las propuestas de descubrimiento y liberación del cuerpo mantienen, explícitamente o no, una lucha contra la naturaleza del cuerpo. En ellas, se pretende negar la evolución lógica - e inevitable- que como seres mortales enfrentamos y emprenden una carrera contra el desgaste natural del cuerpo. Sin embargo, entre ese cuerpo ideal y el cuerpo experimentado cotidianamente existe una distancia considerable. Es por eso que, según el autor, todas esas actividades se producen fuera de los ámbitos cotidianos, mientras que en la vida diaria el comportamiento no se modifica. El cuerpo permanece en su presencia-ausencia, lo que sucede también dentro de dichas prácticas, porque en la mayoría de ellas el cuerpo, en sus aspectos pulsionales no es escuchado. El contacto y la comunicación consigo mismo y con los otros surgen como resultado de la repetición de una técnica aplicada para organizar la relación entre los sujetos. Pero esas técnicas no han nacido a partir del acuerdo común de los individuos implicados en su implementación. El aspecto relacional está en corto circuito, solo se abordan algunos

Gabriela Pérez Cubas, La corporeidad y el poder realizador del actor

R.bras.est.pres., Porto Alegre, v.1, n.2, p. 370-384, jul./dez., 2011.

Disponível em http://www.seer.ufrgs.br/presenca 
aspectos de él, el cuerpo, alter ego, puede otorgarle al sujeto ciertos placeres, aunque sin abandonar el imaginario dualista.

Para el autor, la eclosión de prácticas corporales que proponen un conocimiento alternativo del cuerpo se sitúa en un cruce de caminos entre la necesidad antropológica de luchar contra el fraccionamiento del sujeto y el juego de los signos que cubren al cuerpo. De manera paradójica, afirma Le Bretón, el sujeto se libera por medio de la aprehensión de normas para liberarse, en espacios especialmente preparados para distanciarse de la cotidianeidad y sometiéndose a la guía de un maestro experimentado que le indica cual es el camino de retorno al cuerpo liberado. En esa relación, se reproduce el mismo tipo de sumisión a la autoridad a la que los sujetos están acostumbrados en sus trabajos y en su vida cotidiana en general.

El nuevo imaginario que propone el cuerpo liberado, cuyo surgimiento el autor sitúa a partir de los años sesenta, se impone como el tema predilecto en el discurso social: el cuerpo como lugar estratégico de la reconquista del ser, espacio privilegiado del bien-estar. Producto del proceso cada vez más acelerado de individuación social que se caracteriza por la inversión de la esfera privada, la preocupación por el Yo, la obsolescencia rápida de las referencias y de los valores y la incertidumbre, entre otras, este nuevo imaginario presenta modificaciones, pero sin alterar el paradigma dualista sobre el cual se estructuró. De hecho, separar al cuerpo del sujeto para afirmar luego su liberación es una figura de estilo de un imaginario dualista. Solo podremos decir, -sostiene Le Bretón - que la liberación del cuerpo se ha efectuado cuando desaparezca la preocupación por el cuerpo.

En la actual voluntad de rescatar los aspectos inaprensibles de la corporeidad en tanto carne historiada, de borrar su alteridad, el imaginario social convierte al cuerpo en el lugar de la verdad ontológica, de la transparencia, el cuerpo como suplemento del alma lo que resulta ser no más que un suplemento del símbolo perdido.

Gabriela Pérez Cubas, La corporeidad y el poder realizador del actor

R.bras.est.pres., Porto Alegre, v.1, n.2, p. 370-384, jul./dez., 2011.

Disponível em http://www.seer.ufrgs.br/presenca 


\section{El cuerpo artístico}

Dado que la corporeidad, como unidad sensible, permanece en un lugar de ausencia-presencia en los rituales de la vida cotidiana es razonable pensar, tal como lo hace Le Bretón, que sólo cuando el hombre altera su comportamiento habitual, consigue romper el silencio habitual del cuerpo. La densidad física y sensorial de la corporeidad es recuperada en aquellas circunstancias que salen de lo habitual. En ellas, el individuo puede percibir su cuerpo en una situación orgánica, compleja y distinta que pone todo el organismo en movimiento.

Es en este punto donde las actividades artísticas y particularmente la danza y el teatro pueden construir miradas alternativas. A través de su práctica es posible restablecer el vínculo sensorial y perceptivo del sujeto consigo mismo y de éste con un universo simbólico que sustente su obrar en el mundo.

La cuestión entonces, no es escoger la mejor de las técnicas para aplicar a un proceso de entrenamiento. No se trata de llenar el cuerpo con sistemas apropiados para el desarrollo del movimiento y la expresividad sino, antes bien, la tarea debe orientarse a abrir el espacio para que la corporeidad abandone su lugar de claro-oscuro, un espacio en donde el sujeto reconozca su actividad sensorial, perceptiva y simbólica en cada acto vital.

Cada ser humano posee su propia experiencia del mundo, y es desde su experiencia vital que da sentido a sus acciones. Si nuestro interés, en la calidad de orientadores de la formación expresiva del actor, es contribuir al desarrollo de un artista, se hace necesario valorar sus modos de percibir y comprender el mundo. Será sobre sus maneras de sentir y experimentar el mundo que el actor logrará elaborar su singularidad artística, construyendo su universo poético. Según Le Bretón

[...] estamos en la experiencia sensible del mundo. A cada momento la existencia solicita la unidad de los sentidos [...]. Los sentidos concurren en conjunto para hacer que el mundo resulte coherente y habitable. No son ellos quienes descifran al mundo, sino el individuo a través de su sensibilidad y su educación. Las percepciones sensoriales lo

Gabriela Pérez Cubas, La corporeidad y el poder realizador del actor

R.bras.est.pres., Porto Alegre, v.1, n.2, p. 370-384, jul./dez., 2011.

Disponível em http://www.seer.ufrgs.br/presenca 
ponen en el mundo, pero él es el maestro de la obra (Le Breton, 2007, p. 44).

Se trata de tornar subjetiva la experiencia del actor, de restablecer o de construir la relación sensible del individuo consigo mismo y con su experiencia en el mundo. Pero esta experiencia no se encierra en la visión aislada del sujeto. Aquí la noción de subjetivación trae consigo otro riesgo más. No se trata de la "militarización idiotizada de la subjetividad", como define André Lepecki (Lepecki, 2009, p. 32) a la andanada de discursos que proponen el encierro del sujeto sobre sí mismo respondiendo a las normativas del Sujeto social.

\begin{abstract}
¿Qué es lo que caracteriza este modo o forma de subjetivación? Ante todo, encierra la subjetividad en una experiencia del ser separado del mundo. En la modernidad, la subjetividad queda atrapada en una experiencia solipsista del "ego como el sujeto último para y de la representación" (Courtine, 1991, p. 79 apud Lepecki, 2009, p. 29) que ve el "cuerpo como algo que tiene una existencia independiente y que se rige por leyes inmanentes" (Ferguson, 2000: 7) (...) la centralidad de este sujeto experimenta su ser como plenamente independiente y ontológicamente separado del mundo como constitutivo del proceso moderno de subjetivación (Lepecki, 2009, p. 29).
\end{abstract}

Esta subjetivación está orientada no solo hacia el consumo de productos para acceder al "verdadero goce de vivir", como dice Le Bretón sino también al autismo político de las sociedades - en su más amplia acepción -y en consecuencia a los bienes culturales que ellas producen. Tal subjetivación es la prolongación del paradigma dualista, invertido ahora en la objetivación del cuerpo como alter ego del sujeto, tal como hemos analizado en páginas anteriores.

Por el contrario, el reconocimiento de la subjetividad para el entrenamiento del actor que proponemos aquí coincide con la propuesta de Lepecki cuando afirma:

Mi uso del término "subjetividad" no indica un retorno ni una reapropiación del concepto de "sujeto" [...] Más bien

Gabriela Pérez Cubas, La corporeidad y el poder realizador del actor

R.bras.est.pres., Porto Alegre, v.1, n.2, p. 370-384, jul./dez., 2011.

Disponível em http://www.seer.ufrgs.br/presenca 
debe entenderse como un concepto dinámico, que hace referencia a modalidades de acción (política, de deseo, afectiva, coreográfica) que revelan "un proceso de subjetivación, es decir la producción de un modo de existencia (que) no puede confundirse con un sujeto" (Deleuze, 1995:98, apud Lepecki, 2009,p. 25) La subjetividad debe entenderse como un poder realizativo (performativo), como la posibilidad de que la vida sea constantemente inventada y reinventada, como "un modo intensivo y no de un sujeto personal"(1995:99) (Lepecki, 2009, p. 24).

Para Lepecki, este concepto de subjetividad se aproxima a las "tecnologías del ser", las cuales, según Foucault,

Permiten a los individuos efectuar por sus propios medios [...] un cierto número de operaciones sobre sus propios cuerpos y almas, pensamientos, conducta y forma de ser para transformarse con el fin de alcanzar un cierto estado de felicidad (Lepecki, 2009, p. 25).

Propongo entonces, pensar los métodos de entrenamiento cinestésico y expresivo del actor como un modo de acceso y estimulación del poder realizador y performativo de los individuos, en donde cada sujeto descubra y elabore sus propias tecnologías de ser, orientadas en este caso dentro de las lógicas espacio temporales que la realidad escénica supone.

Esta tarea no implica la remoción de métodos preexistentes. Aludo aquí al Método de las Acciones físicas, por ejemplo, cuyo poder realizador ha sido lúcidamente analizado por Raúl Serrano en la Argentina; y también a la noción de entrenamiento propuesta por Eugenio Barba, cuyo principal objetivo es el descubrimiento de las lógicas que articulan las acciones del actor. Pensar a la corporeidad del actor como la construcción simbólica a partir de la cual el sujeto elaborará otros símbolos y otras formas, reconocerla como el modo de ser y estar del sujeto en el mundo no plantea excluir la aplicación de otros métodos de entrenamiento del actor. Supone si, reorientar el encuadre conceptual a través del cual se abordan esos métodos y

Gabriela Pérez Cubas, La corporeidad y el poder realizador del actor

R.bras.est.pres., Porto Alegre, v.1, n.2, p. 370-384, jul./dez., 2011.

Disponível em http://www.seer.ufrgs.br/presenca 
comprender el proceso creativo del actor como un poder realizador en el que cada artista irá construyendo sus propias tecnologías de ser en la escena. Porque el problema no es la falta de técnicas, sino la manera como cada uno de nosotros entiende y construye sus saberes sobre el individuo y el cuerpo.

\begin{abstract}
Notas
1 Según Le Bretón, el comportamiento popular en las civilizaciones medievales y particularmente em las celebraciones del carnaval podía entenderse como una fiesta comunitaria: "en la que el conjunto de los hombres tiende, provisoriamente, a la comunión, más allá de las tensiones de la vida social" El cuerpo festivo del medioevo se oponía al cuerpo individualizado de la modernidad: El cuerpo grotesco está formado por salientes, protuberancias, desborda de vitalidad, se mezcla con la multitud, indiscernible, abierto, en contacto con el cosmos, insatisfecho con los limites que permanentemente transgrede". ( Le Bretón, 1995, p.30)

2 De acuerdo con Le Breton, es entre el surgimiento de Vesalio - médico que instituyo las disecciones de cadáveres como forma de conocimiento del cuerpo humano - autor de De Humani Corporis Fábrica, aparecido en 1543, donde el cuerpo separado del sujeto, es analizado en su funcionamiento mecanico, y el surgimiento de Descartes con el "Discurso del Método" y las "Meditaciones Metafísicas" - donde eleva el pensamiento al mismo tiempo que denigra el cuerpo - que se produce el duelo en el pensamiento occidental. El hombre se divorcia del cuerpo y de la idea de pertenencia a la naturaleza, valorizando la racionalidad como principio epistemológico. Posteriormente, los descubrimientos de Copérnico y Galileo reafirmarán el predominio del racionalismo, dando al pensamiento humano la posibilidad de comprender el mundo a través del calculo matemático (Le Breton, 1995, p. 52).
\end{abstract}

\title{
Referencias
}

FOUCAULT, Michel. Vigilar y Castigar. Buenos Aires: Siglo XXI, 2005.

LE BRETÓN, David. Antropología del Cuerpo y Modernidad. Buenos Aires: Nueva Visión, 1995.

LE BRETÓN, David. Eı Sabor del Mundo. Una antropología de los sentidos. Buenos Aires: Buenos Aires, 2005.

LEPECKI, André. Agotar la Danza. Performance y política del movimiento. Alcalá: Centro Coreográfico Galego/Mercat de les Flors/Universidad de Alcalá, 2009.

MATOSO, Elina. El Cuerpo, Territorio de la Imagen. Buenos Aires: Letra Viva, 2001.

Gabriela Pérez Cubas, La corporeidad y el poder realizador del actor

R.bras.est.pres., Porto Alegre, v.1, n.2, p. 370-384, jul./dez., 2011.

Disponível em http://www.seer.ufrgs.br/presenca 
Gabriela Perez Cubas é mestre em Artes Cênicas pela Universidade Federal da Bahia, no Brasil. É professora da área de expressão corporal para o ator na Universidad Nacional del Centro de la Provincia de Buenos Aires, em Tandil na Argentina.

e-mail: gperez@arte.unicen.edu.ar

Recebido em Setembro de 2011

Aprovado em Novembro de 2011

Gabriela Pérez Cubas, La corporeidad y el poder realizador del actor

R.bras.est.pres., Porto Alegre, v.1, n.2, p. 370-384, jul./dez., 2011.

Disponível em http://www.seer.ufrgs.br/presenca 